\title{
Comparison of Smart Charging and Battery Energy Storage System for a PV Prosumer with an EV
}

\author{
Calearo, Lisa; Ziras, Charalampos; Sevdari, Kristian; Marinelli, Mattia
}

Published in:

Proceedings of ISGT Europe 2021

Link to article, DOI:

10.1109/ISGTEurope52324.2021.9640120

Publication date:

2021

Document Version

Peer reviewed version

Link back to DTU Orbit

Citation (APA):

Calearo, L., Ziras, C., Sevdari, K., \& Marinelli, M. (2021). Comparison of Smart Charging and Battery Energy Storage System for a PV Prosumer with an EV. In Proceedings of ISGT Europe 2021 IEEE.

https://doi.org/10.1109/ISGTEurope52324.2021.9640120

\section{General rights}

Copyright and moral rights for the publications made accessible in the public portal are retained by the authors and/or other copyright owners and it is a condition of accessing publications that users recognise and abide by the legal requirements associated with these rights.

- Users may download and print one copy of any publication from the public portal for the purpose of private study or research.

- You may not further distribute the material or use it for any profit-making activity or commercial gain

- You may freely distribute the URL identifying the publication in the public portal 


\title{
Comparison of Smart Charging and Battery Energy Storage System for a PV Prosumer with an EV
}

\author{
Lisa Calearo, Charalampos Ziras, Kristian Sevdari, Mattia Marinelli \\ Department of Electrical Engineering \\ Technical University of Denmark (DTU) \\ Roskilde, Denmark \\ \{lica; chazi; krisse; matm\}@elektro.dtu.dk
}

\begin{abstract}
Battery energy storage systems (BESSs) for residential photovoltaic (PV) prosumers are becoming more popular with the reduction of battery prices, as a means of increasing self-consumption. When considering prosumers that also own an electric vehicle (EV), smart charging can also fulfill the same objective. This paper assesses the benefits of a PV prosumer with an EV under two options: installing a BESS or applying smart charging. Smart charging is applied with the goal of reducing energy imports by charging the $\mathrm{EV}$ when there is excess of production. The effect of using a BESS of varying inverter and storage size is also investigated, when operated under a simple energy import minimization logic. We use a yearly dataset of real 5-min measurements collected from a Danish household with a 6 kWp PV plant. The prosumer also owns a $62 \mathbf{k W h}$ Nissan LEAF. We find that smart charging increases self-consumption from $29 \%$ to $54 \%$, leading to yearly savings of $220 €$. Through a sensitivity analysis we find that a BESS of $8 \mathrm{kWh} / 2 \mathrm{~kW}$ yields similar yearly results. Given the approximately 20 times higher payback period of the BESS, we conclude that smart charging is economically much more attractive.
\end{abstract}

Index Terms-battery energy storage system, electric vehicle, photovoltaic, prosumer, smart charging.

\section{INTRODUCTION}

In the effort of reducing carbon emissions and transforming the electricity system into a fully sustainable one, the increase of the share of renewable energy and the electrification of the transportation sector are key factors. Flexibility plays a major role in this development, and can be provided by battery energy storage systems (BESSs) [1] or via demand response, primarily through electric vehicles (EVs) [2]. Nevertheless, EVs are part of both the problem and the solution [3], as their large storage capacity offers flexibility, but the associated charging needs can potentially stress local grids [4].

The decrease of battery prices during the last decade is making EVs and BESSs more economically attractive. Among others, the rise of electricity prices due to policy implementations, together with the decrease of photovoltaic (PV) system costs, are motivating private households to become prosumers and to increase their self-consumption. The possibility to become more independent from the grid is also an opportunity for customers to reduce their risk exposure to increases of electricity prices or tariffs/taxes. However, given that PV production is predominant during the day time, whereas household consumption is mostly concentrated during the evening, a large part of the PV production is sold to the grid, instead of directly being used by the household. In countries such as Denmark, where tariffs and taxes account for approximately $80 \%$ of the final residential electricity price, the import price per $\mathrm{kWh}$ can be several times larger than the price being paid for exporting electricity [5]. Therefore, in the absence of a dedicated premium tariff, it is logical that prosumers prioritize the use of electricity locally. In general, this can be done by shifting as much consumption as possible during the day time.

PV production often does not coincide with the bulk of a household's inflexible consumption or an EV's uncontrolled charging demand, leading to relatively low self-consumption. In order to increase the self-consumption of the PV prosumer, there are two main options: the modulation of EV consumption and the usage of a BESS.

On the one hand, researchers investigate the use of EVs to provide flexibility by considering smart (i.e., unidirectional) charging [6] and vehicle-to-X [7]. Smart charging analyses are often investigated for non-residential parking areas, where multiple chargers can be controlled and provide flexibility [8]. When future vehicles will be equipped with on-board bidirectional chargers, the investigation of a V2X case becomes more interesting. Few studies investigate the residential smart charging possibility, as in [9], [10] where a distributed and a centralized EV scheme are implemented to minimize grid export from residential customers. In [11], a demonstration test of EV smart charging controlling the energy production and consumption of an energy community is described.

On the other hand, there is a large interest in PV prosumers with BESSs, with regards to scheduling and optimization [12] [14]. In [15], the authors investigate the self-consumption of Swedish single-family households/dwellings, providing a sensitivity analysis of PV installation and battery of different sizes. In [16], an optimal storage system sizing based on equivalent circuit modeling is proposed, where the main goal is to balance solar production and load demand. In [17], a technical approach based on the optimization of the selfsufficiency is proposed to size PV-battery systems. In [18], a Romanian study case with a PV plant and different BESSs are compared, showing that despite the higher self-consumption with larger batteries, the smaller ones are, for the time being, more economically viable.

In this article we focus on the increase of self-consumption, 
also referred to self-sufficiency, and associated prosumer savings comparing two options: EV smart charging and BESS operation. Both cases are based on the consideration of realdata from a Danish PV prosumer, where an EV with fixed idle time and distance driven is introduced. The main contributions of the manuscript can be summarized as follows:

- Investigation of the effect of EV smart charging and BESSs in terms of self-consumption and savings, using real data with 5 minute resolution for both consumption and production.

- Self-consumption and savings sensitivity analysis of different BESSs sizes.

- Assessment and comparison of the two options, with a focus on economic viability.

The rest of the paper is structured as follows. Section II focuses on the methodology formulation of the EV smart charging and BESS control logic. Section III provides an overview of the study case. Section IV analyses the results and Section V concludes the manuscript with the main outcomes.

\section{Methodology}

Our goal is to evaluate and compare the increase in selfconsumption when smart charging or a BESS are included on a residential prosumer equipped with a PV and an EV. The prosumer is represented by an inflexible household consumption (HC), a rooftop PV production and an EV under dumb charging, where the vehicle charges with the maximum possible charging power as soon as it is plugged-in at home. For the $\mathrm{HC}$ and the PV production we rely on the use of historical data, whereas EV consumption is derived from vehicle usage and needs in Denmark. We analyse the increase in self-consumption first in relation to the implemented smart charging logic, and second as a sensitivity analysis on the energy and power capacity of an added BESS.

We fist present the EV and BESS formulations in subsection II-A. In subsection II-B we present generic controllers for the $\mathrm{EV}$ and the BESS that can be easily implemented in practice. To make the controllers more robust and friendlier for implementation, no optimization, considerations for hourly energy price variations or forecasting are employed. The goal of the smart charging logic and the BESS controller are to maximize self-consumption, which is an objective closely linked to prosumer cost minimization due to the high ratio of import/export prices. Given these components, and a yearly prosumer dataset with 5-min $\mathrm{HC}$ and $\mathrm{PV}$ measurements, in subsection II-C we show how we can conduct the aforementioned sensitivity analysis to derive the yearly self-consumption and the related savings.

\section{A. Electric vehicle and BESS formulation}

1) $E V$ : We consider unidirectional $\mathrm{EV}$ charging, characterized by charging power $P_{t}^{\mathrm{EVc}}$ and state-of-charge (SOC) $S O C_{t}^{\mathrm{EV}}$ in each time step $t$. The charging power is subject to energy losses, according to a charger efficiency $\eta_{\mathrm{c}}$, which is a function of the charging power. SOC evolution is described by

$$
S O C_{t}^{\mathrm{EV}}=S O C_{t-1}^{\mathrm{EV}}+\eta_{\mathrm{c}}\left(P_{t-1}^{\mathrm{EV} \mathrm{c}}\right) P_{t-1}^{\mathrm{EV} \mathrm{c}} \Delta t,
$$

where $\Delta t$ is the time step's duration in normalized terms, i.e., $\Delta t=1 / 12$ for a 5 -min time step. In this work we are only interested in accounting for the overall energy usage of the vehicle. To account for EV driving needs we subtract half of the equivalent total energy usage from the SOC as soon as the EV plugs out and half when the EV plugs in. For ease of notation, this SOC reduction is not included in the formulation (1), but it is accounted in the model.

2) BESS: The BESS is composed of a battery pack and an inverter, and is characterized by the charging $P_{t}^{\mathrm{Bc}}$ and discharging $P_{t}^{\mathrm{Bd}}$ power and $S O C_{t}^{\mathrm{B}}$. The power values correspond to the AC side of the BESS. Since inverter losses are dominant, we neglect battery losses and only account for inverter charging $\eta_{\mathrm{Bc}}$ and discharging $\eta_{\mathrm{Bd}}$ efficiency, which are functions of the corresponding power values. The SOC evolution is described by

$$
\begin{aligned}
S O C_{t}^{\mathrm{B}} & =S O C_{t-1}^{\mathrm{B}}+P_{t-1}^{\mathrm{Bc}} \eta_{\mathrm{Bc}}\left(P_{t-1}^{\mathrm{Bc}}\right) \Delta t \\
& -P_{t-1}^{\mathrm{Bd}} / \eta_{\mathrm{Bd}}\left(P_{t-1}^{\mathrm{Bd}}\right) \Delta t .
\end{aligned}
$$

\section{B. Controllers design}

Two controllers are designed in this section: one for the EV smart charging logic and one for the BESS.

1) Electric vehicle: This section presents how the (unidirectional) EV charging power is derived. We propose a simple smart charging logic, characterized by three different windows of charging behaviour.

- driving window: the vehicle is not plugged-in and no charging occurs. During this window the vehicle could be driven or is parked on another location;

- smart window: the vehicle is plugged-in and smart charging is applied. The vehicle charges only if there is sufficient excess of net PV production $P_{t}^{\text {net }}$ (PV generation minus $\mathrm{HC}$ ) to allow charging by respecting the communication standard IEC 61851 [19]. According to the standard, the EV can charge with a minimum $\underline{P}$ and a maximum $\bar{P}$ power. Depending on $P_{t}^{\text {net }}$ and IEC limitations, three charging regimes are defined:

$$
\begin{aligned}
& \text { - if } P<P_{t}^{\text {net }}<\bar{P} \text {, then } P_{t}^{\mathrm{EVc}}=P_{t}^{\text {net }} \\
& \text { - if } P_{t}^{\text {net }}<\underline{P} \text {, then } P_{t}^{\mathrm{EVc}}=0 ; \\
& \text { - if } P_{t}^{\text {net }}>\bar{P} \text {, then } P_{t}^{\mathrm{EVc}}=\bar{P} \text {. }
\end{aligned}
$$

To avoid accelerated degradation, the battery is charged to a maximum SOC $\left(\overline{S O C}^{\mathrm{EV}}\right)$;

- urgent window: the vehicle is plugged-in and charges with $P^{\text {set }}$. This control mode ensures that the EV will have a SOC of at least $S O C^{\text {set }}$ upon departure and $P^{\text {set }}<\bar{P}$ is chosen to avoid unnecessarily loading the grid.

We consider that the EV charger is capable of stopping the charging process when the available power drops below the minimum rate, and start it again when this limit is exceeded. Fig. 1 provides the flowchart of the smart charging logic. 


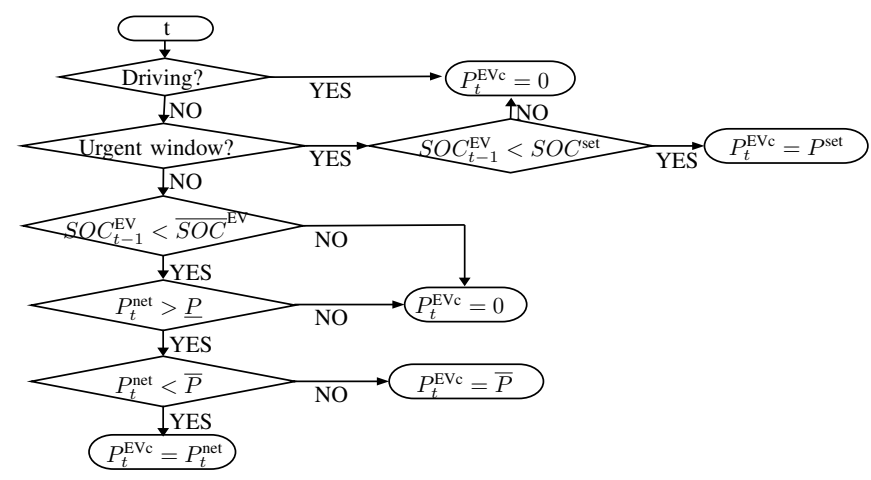

Fig. 1: Flowchart of the smart charging logic.

During the days that the vehicle is not driven, the smart window can be constantly applied, whereas when the vehicle is driven, the EV may enter both control modes.

2) BESS: The EV dumb charging power is given as input to the BESS controller, together with PV production and $\mathrm{HC}$. The controller first stores any excess available power to the BESS and then exports the remainder to the grid. Similarly, any deficit is first covered by the BESS, and if this is not enough then energy is also imported from the grid. Fig. 2 presents the flowchart to derive the charging and discharging power of the BESS for each time step $t$. The available power $P_{t}^{\mathrm{av}}$, i.e. the difference between the net demand and the charging power of the $\mathrm{EV}$, is first determined

$$
P_{t}^{\mathrm{av}}=P_{t}^{\mathrm{net}}-P_{t}^{\mathrm{EVc}}=P_{t}^{\mathrm{PV}}-P_{t}^{\mathrm{HC}}-P_{t}^{\mathrm{EV} \mathrm{c}} .
$$

If $P_{t}^{\text {av }} \geq 0$, this excess power should be stored in the BESS, if possible. First, the corresponding energy $P^{\text {av }} \Delta t$ is compared with the upward $(U)$ energy charging potential

$$
U=\overline{S O C}^{\mathrm{B}}-S O C_{t-1}^{\mathrm{B}} \text {. }
$$

$U$ is the energy that can be stored in the battery until the maximum SOC $\overline{S O C}^{\mathrm{B}}$ is reached. In a similar way, the downward $(D)$ energy potential is defined as the energy that can be withdrawn from the battery so as not to reduce the SOC below $\underline{S O C^{\mathrm{B}}}$

$$
D=S O C_{t-1}^{\mathrm{B}}-\underline{S O C^{\mathrm{B}}} .
$$

If $U$ is large enough to store $P_{t}^{\text {av }} \Delta t$, an additional check is needed to ensure that power $P_{t}^{\text {av }}$ does not exceed inverter power capacity $P^{\text {inv }}$. If this capacity is smaller, the BESS will be charged with $P^{\text {inv }}$ and the remainder power will be fed to the grid. Finally, if $U$ is not large enough, then only a part of the excess production can flow into the BESS. Pinv is compared with the corresponding power $U / \Delta t$, and if it is larger then the BESS can charge at a rate $U / \Delta t$, otherwise it can only charge by $P^{\text {inv }}$. Similar considerations apply when there is a deficit $\left(P_{t}^{\text {av }}<0\right)$. Note that charging and discharging are mutually exclusive quantities, so only the non-zero value is shown in Fig. 2. Furthermore, import $P_{t}^{\text {im }}$ and export power $P_{t}^{\text {ex }}$ from/to the grid (which are also mutually exclusive) are omitted from the flowchart and are calculated as follows

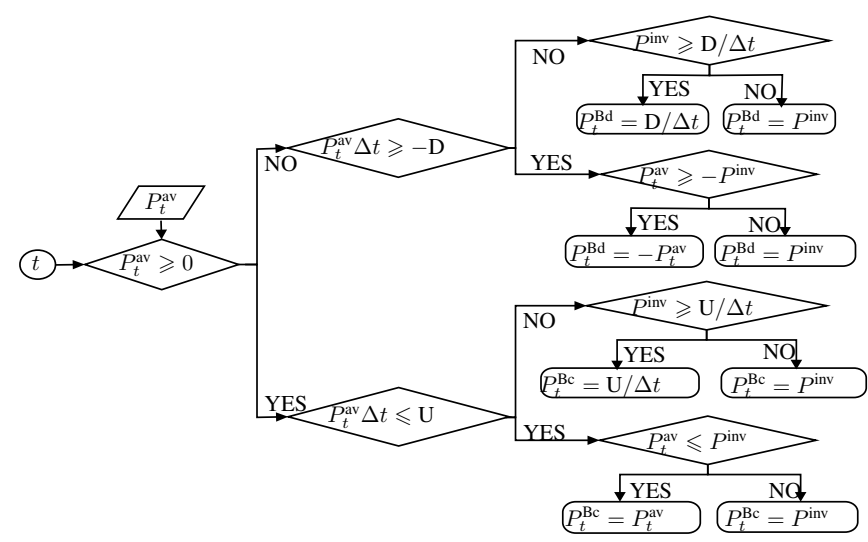

Fig. 2: Flowchart charging/discharging power BESS derivation.

$$
\begin{aligned}
& P_{t}^{\mathrm{im}}=\max \left(-P_{t}^{\mathrm{av}}+P_{t}^{\mathrm{Bc}}-P_{t}^{\mathrm{Bd}}, 0\right), \\
& P_{t}^{\mathrm{ex}}=\max \left(P_{t}^{\mathrm{av}}-P_{t}^{\mathrm{Bc}}+P_{t}^{\mathrm{Bd}}, 0\right) .
\end{aligned}
$$

\section{Self-consumption, savings and losses}

To compare the benefits of smart charging with those of the BESS, we determine the self-consumption and the savings that the two solutions can provide. Self-consumption $(S C)$ is defined as the ratio of the consumed energy covered by local production divided by the total consumption.

$$
S C=\sum_{t=1}^{T} \frac{P_{t}^{\mathrm{HC}}+P_{t}^{\mathrm{EVc}}-P_{t}^{\mathrm{im}}}{P_{t}^{\mathrm{HC}}+P_{t}^{\mathrm{EVc}}},
$$

where $T$ is the investigated period of time. Costs $(C)$ are given in both cases of using smart charging or a BESS by

$$
C=\sum_{t=1}^{T}\left(c_{t}^{\mathrm{b}} P_{t}^{\mathrm{im}} \Delta t\right)-\sum_{t=1}^{T}\left(c_{t}^{\mathrm{s}} P_{t}^{\mathrm{ex}} \Delta t\right),
$$

where $c^{\mathrm{s}}$ and $c^{\mathrm{b}}$ are the selling and buying prices per $\mathrm{kWh}$ of energy, respectively. Eq. (8) is also used to calculate the baseline cost, i.e., the cost without the addition of a smart charger or a BESS. Savings are calculated by subtracting the resulting costs in each case from the baseline cost. When smart charging is considered, there is a single $C$ value to determine. When a BESS is used, we need to consider different sizes of the storage system. A sensitivity analysis is thus conducted, which allows us to calculate prosumer costs (and thus savings) under different combinations of battery and inverter sizes.

Another important aspect to consider is the increased amount of losses due to smart charging or the use of a BESS. Dumb charging happens at the charger's nominal capacity with maximum efficiency, whereas smart charging increases charging losses due to operation in lower-efficiency regions. The charging losses $L^{\mathrm{EV}}$ are derived by using (9), whereas inverter losses $L^{\mathrm{B}}$ are given by (10).

$$
\begin{gathered}
L^{\mathrm{EV}}=\sum_{t=1}^{T}\left(P_{t}^{\mathrm{EV} c}-P_{t}^{\mathrm{EVc}} \eta_{\mathrm{c}}\left(P_{t}^{\mathrm{EVc}}\right)\right) \Delta t \\
L^{\mathrm{B}}=\sum_{t=1}^{T}\left(P_{t}^{\mathrm{Bc}}-P_{t}^{\mathrm{Bc}} \eta_{\mathrm{Bc}}\left(P_{t}^{\mathrm{Bc}}\right)+P_{t}^{\mathrm{Bd}}-\frac{P_{t}^{\mathrm{Bd}}}{\eta_{\mathrm{Bd}}\left(P_{t}^{\mathrm{Bd}}\right)}\right) \Delta t .
\end{gathered}
$$




\section{CASE STUDY}

\section{A. Case study description}

A Danish prosumer, characterized by a number of domestic appliances, a $6 \mathrm{kWp}$ PV plant and a Nissan LEAF $62 \mathrm{kWh}$ EV is considered in this paper. The EV charger is single-phase, with maximum charging power of $3.68 \mathrm{~kW}$ and the possibility to provide unidirectional smart charging, in the range of 6-16A [19]. A simplified system configuration is provided in Fig. 3. The figure provides both the power and communication flows and the location of the energy and smart meters used for the data collection. It should be noted that the energy supplier meter, although measuring values every second, stores data with an hourly resolution [5]. Therefore, an additional meter (Fronius smart meter) was installed to save data with a finer resolution (five minutes). The smart meter sends the data to the PV inverter data logger (via RS-485). Also, the figure shows the smart charger, BESS components (red squares), and their behind the meter location.

\section{B. Investigated scenarios}

The following three scenarios will be investigated:

1) Base case: this scenario is the initial situation, where PV production, $\mathrm{HC}$ and EV dumb charging are considered;

2) Smart charging: in this scenario the PV production and $\mathrm{HC}$ remain the same, whereas the smart charging logic is considered for charging the $\mathrm{EV}$;

3) BESS: similar to the base case (EV dumb charging), but different BESS sizes are introduced.

For simplicity, $c^{\mathrm{b}}$ and $c^{\mathrm{s}}$ are considered constant and equal to $0.25 € / \mathrm{kWh}$ and $0.03 € / \mathrm{kWh}$, respectively, which are the current (2020) average prices for a residential customer with a net billing scheme [5]. Furthermore, we are considering summation metering at the point of common coupling. In this regard, single- and three- phase loads are not differentiated, and the same goes for the EV charger and BESS inverter.

\section{Data analysis}

1) PV and base consumption: Data is provided for a one year period (Sep 12019 to Aug 31 2020) with 5 minutes resolution. An in-depth analysis of the data is provided in [5]

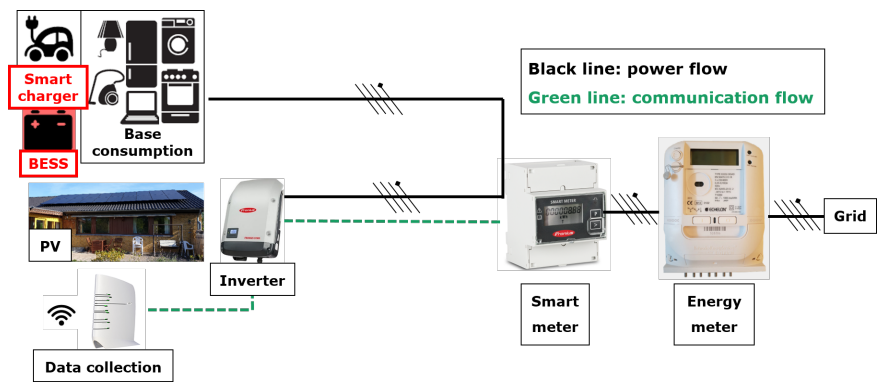

Fig. 3: System configuration including power and communication flows. Modified from [5].
TABLE I: $3.68 \mathrm{~kW}$ charger efficiency.

\begin{tabular}{|l|c|c|c|c|}
\hline$P^{\mathbf{E V c}}[\mathbf{k W}]$ & 1.38 & 2.30 & 2.99 & 3.68 \\
\hline$\eta_{\mathbf{c}}\left(P^{\mathbf{E V c}}\right)[\%]$ & 80 & 86 & 88 & 90 \\
\hline
\end{tabular}

TABLE II: Charging efficiency of the Fronius inverter [21]

\begin{tabular}{|l|c|c|c|c|c|c|c|c|}
\hline$P^{\mathbf{B c}}[\%]$ & 5 & 10 & 20 & 25 & 30 & 50 & 75 & 100 \\
\hline$\eta_{\mathbf{B c}}\left(P^{\mathbf{B c}}\right)[\%]$ & 92.6 & 95.6 & 97.1 & 97.5 & 97.7 & 98.0 & 98.0 & 97.9 \\
\hline
\end{tabular}

2) EV data: For the EV driving/charging profile it is assumed that a $62 \mathrm{kWh}$ Nissan LEAF is driven on Wednesday, Thursday and Sunday, with respectively 40,40 and $80 \mathrm{~km}$, and the user leaves home at 8.00 and returns at 18.00. During the remaining time the vehicle is plugged-in at home, charging or available for smart charging. This driving behaviour takes into consideration a lower amount of $\mathrm{km}$ driven than the average Danish in 2019 of $45 \mathrm{~km} /$ day [20]. This decrease reflects the increased home-working due to the Covid-19 effect, which led to a significant reduction in commuting [3], [20].

The considered charger has a charging range of $6-16 \mathrm{~A}$, which follows the communication standard IEC 61851 [19]. When dumb charging is considered, the EV charges when it is plugged-in with a maximum charging power of $3.68 \mathrm{~kW}(16 \mathrm{~A}$ . $230 \mathrm{~V}$, considering a power factor of 1) and until $\overline{S O C}^{\mathrm{EV}}=$ $90 \%$ is reached. The internal charger efficiency of the vehicle $\left(\eta_{\mathrm{c}}\left(P_{t}^{\mathrm{EVc}}\right)\right)$ is 0.8 at the minimum and 0.9 at the maximum charging power with an almost linear increase. These values were obtained by the authors after conducting measurements. When smart charging is considered, constraints on the start/end charging time and charging power are included, as described in Section II-B1. The vehicle can charge with smart logic during the entire day for the days when it is not driven, whereas it can smart charge only few hours during the remaining days. During smart charging the vehicle charges if there is an excess of PV production above the minimum $\frac{P}{P}=1.38 \mathrm{~kW}(6 \mathrm{~A}$. $230 \mathrm{~V})$ up to $\bar{P}=3.68 \mathrm{~kW}$, until $\overline{S O C}^{\mathrm{EV}}=90 \%$ is reached. To avoid having a fully discharged vehicle when the user needs to drive, if the vehicle has a SOC lower than $50 \%\left(\right.$ SOC $\left.^{\text {set }}\right)$ at midnight of the driving day, the urgent charging mode takes over and can charge the vehicle up to $50 \%$ until 8.00 with offset charging power: $P^{\text {set }}=2.53 \mathrm{~kW}(11 \mathrm{~A} \cdot 230 \mathrm{~V})$.

3) BESS data: To avoid accelerated degradation, the battery is operated between $\underline{S O C^{\mathrm{B}}}=10 \%$ and $\overline{S O C}^{\mathrm{B}}=90 \%$. The inverter is considered to have a power-dependent efficiency. The inverter is assumed to be a Fronius type [21], as the one of the PV in Fig. 3. Therefore, the efficiency data of this inverter is considered and is provided in Table II for the charging case. Since only some operating points are provided, the remaining points are derived with linear interpolation. The discharging efficiency is the inverse of the charging one.

\section{RESULTS}

In this section first we visualize the effect of employing smart charging and the use of a BESS over a week, and discuss the increase in self-consumption and the obtained savings over 
one year. Next, we assess and compare the performance of the two solutions, both in technical and economic terms.

\section{A. Smart charging}

Fig. 4 provides the profiles of the PV production, $\mathrm{HC}$ and EV charging profile during week 11 (9th-15th of March) of 2020. When dumb charging is considered (top plot), the vehicle starts charging at 18:00 when it is plugged-in, with $3.68 \mathrm{~kW}$ and up to the maximum SOC of $55.8 \mathrm{kWh}$. When smart charging is considered (bottom plot), the vehicle charges if there is net generation, and this is large enough to reach the minimum charging limit of $1.38 \mathrm{~kW}$ (Monday, Tuesday, Friday and Saturday); the user drives on Wednesday, Thursday and Sunday, thus the vehicle will enter on urgent window at midnight of the same days to cover the missing energy until the minimum SOC of $31.0 \mathrm{kWh}$ is reached.

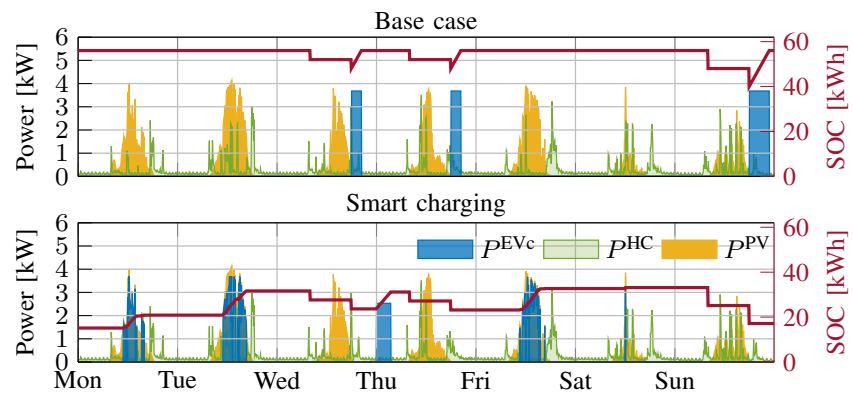

Fig. 4: Comparison charging behaviour with normal (top plot) and smart charging (bottom plot).

On a yearly basis, self-consumption is increased from $29 \%$ to $54 \%$ when smart charging is applied, resulting in savings equal to $221 €$ /year.

\section{B. BESS}

Different combinations of BESS sizes are here investigated. The power of the inverter $\left(P^{\mathrm{inv}}\right)$ varies from 1 to $6 \mathrm{~kW}$ with 1 $\mathrm{kW}$ steps, whereas the battery capacity $\left(C^{\mathrm{B}}\right)$ varies from 2 to $16 \mathrm{kWh}$ with $2 \mathrm{kWh}$ steps. Fig. 5 compares week 11 of 2020 in the case of the smallest $\operatorname{BESS}\left(P_{\mathrm{s}}^{\mathrm{B}}\right)$ with $P^{\mathrm{inv}}=1 \mathrm{~kW}$ and $C^{\mathrm{B}}=2 \mathrm{kWh}$, and of the largest $\operatorname{BESS}\left(P_{1}^{\mathrm{B}}\right)$ with $P^{\text {inv }}=6$ $\mathrm{kW}$ and $C^{\mathrm{B}}=16 \mathrm{kWh}$. HC, $\mathrm{PV}$ and $\mathrm{EV}$ profiles are the same in both cases. $P^{\mathrm{B}}$ is the difference between discharging $\left(P^{\mathrm{Bd}}\right)$ and charging $\left(P^{\mathrm{Bc}}\right)$ power.

In Fig. 6 the different BESS sets are compared in terms of self-consumption and savings per year. On a yearly basis, selfconsumption is increased from $29 \%$ to $41-66 \%$ depending on

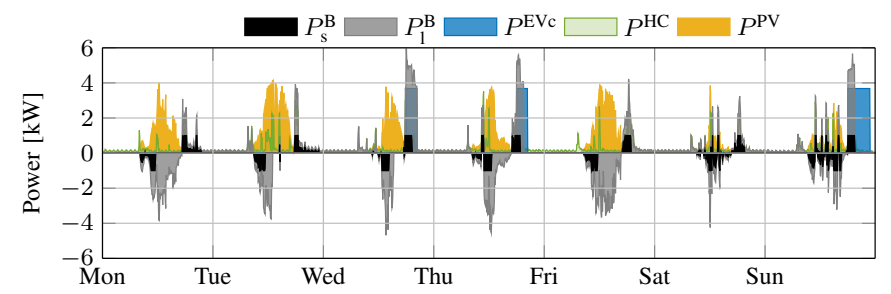

Fig. 5: Comparison of BESS profiles during week 11 of 2020.
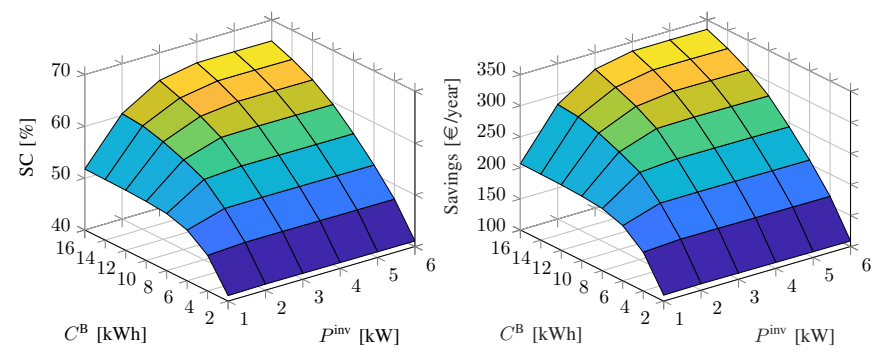

Fig. 6: Comparison of self-consumption and yearly savings of the different battery-inverter sets.

the BESS size, resulting in savings equal to $110-335 €$ /year. It is interesting to note that the increase on self-consumption and savings by using an inverter larger than $3 \mathrm{~kW}$ is not significant.

\section{Comparison and discussion}

Both solutions increase self-consumption and savings compared to the base case. Table III summarizes the main outputs, comparing the base case with smart charging and three BESSs: the smallest $(2 \mathrm{kWh} / 1 \mathrm{~kW})$, the largest $(16 \mathrm{kWh} / 6 \mathrm{~kW})$ and the one whose savings and self-consumption are comparable with smart charging $(8 \mathrm{kWh} / 2 \mathrm{~kW})$.

Smart charging and BESS operation introduce additional losses. The former due to the modulation of the charging power and the latter primarily due to the inverter. These additional losses are $85 \mathrm{kWh}$ for smart charging and $27-105$ $\mathrm{kWh}$ for the BESS. With smart charging the average SOC of the EV battery is also decreased to $57 \%$ (compared to $88 \%$ with dumb charging, which is also applied when the BESS is used), which may have a positive effect on the battery lifetime. Differently, when introducing a BESS the number of cycles is deemed more relevant for the battery lifetime. Increasing the inverter size with the same battery capacity, the number of cycles increases, whereas the opposite happens when increasing the battery size with the same inverter.

One of the most important aspects from the prosumer's point of view is the economic viability of the solution. A smart charging infrastructure of $3.68 \mathrm{~kW}$ may cost twice as much

TABLE III: Yearly results comparison of base case with smart charging and three different BESS sizes.

\begin{tabular}{|l|r|r|r|r|r|}
\cline { 2 - 6 } \multicolumn{1}{c|}{} & $\begin{array}{c}\text { Base } \\
\text { case }\end{array}$ & $\begin{array}{c}\text { Smart } \\
\text { charging }\end{array}$ & $\begin{array}{c}2 \mathrm{kWh} \\
1 \mathrm{~kW}\end{array}$ & $\begin{array}{c}8 \mathrm{kWh} \\
2 \mathrm{~kW}\end{array}$ & $\begin{array}{c}16 \mathrm{kWh} \\
6 \mathrm{~kW}\end{array}$ \\
\hline SC [\%] & 29.01 & 54.33 & 41.06 & 55.51 & 65.96 \\
\hline Energy to grid [kWh] & 4798 & 3699 & 4269 & 3626 & 3149 \\
\hline Energy from grid [kWh] & 2954 & 1938 & 2453 & 1851 & 1416 \\
\hline Energy to EV [kWh] & 1851 & 1934 & 1851 & 1851 & 1851 \\
\hline Energy in EV [kWh] & 1666 & 1661 & 1666 & 1666 & 1666 \\
\hline$L^{\mathrm{EV}}[\mathrm{kWh}]$ & 185.1 & 272.3 & 185.1 & 185.1 & 185.1 \\
\hline$L^{\mathrm{B}}[\mathrm{kWh}]$ & - & - & 26.56 & 65.82 & 105.5 \\
\hline$L^{\mathrm{EV}}+L^{\mathrm{B}}[\mathrm{kWh}]$ & 185.1 & 272.3 & 211.7 & 250.9 & 290.6 \\
\hline Average $S O C^{\mathrm{EV}}[\%]$ & 88.14 & 57.43 & 88.14 & 88.14 & 88.14 \\
\hline Average $S O C^{\mathrm{B}}[\%]$ & - & - & 40.57 & 45.05 & 44.25 \\
\hline Cycles number BESS & - & - & 257.5 & 142.1 & 99.59 \\
\hline$C$ [€ $]$ & 594.7 & 373.6 & 485.1 & 354.0 & 259.7 \\
\hline Savings $[€]$ & - & 221.0 & 109.5 & 240.6 & 335.0 \\
\hline
\end{tabular}


as a 'dumb' charger of the same size, e.g. $400 €$ for a dumb charger [22] against $900 €$ for a smart one [21], [23]. The price of a BESS is a function of the battery size, with larger batteries costing more, but with a lower price per $\mathrm{kWh}$ of capacity. Considering that the price of a $8 \mathrm{kWh} / 2 \mathrm{~kW}$ BESS, which yields similar savings to the prosumer, is approximately $10000 €[24]$, the payback time would be approximately 20 times higher than that of the smart charger. Even if a higher smart charger cost with more advanced capabilities is considered, a BESS is clearly less attractive economically. With the current prices, the payback period in our case study is around 2 years for a smart charger (compared to installing a 'dumb' charger) and 40 for a BESS, far exceeding system lifetime. It is possible that a more sophisticated use of the battery, e.g., for spot price optimization, could increase savings, but the 20 to 1 payback ratio makes smart charging much more attractive under the current circumstances.

\section{CONCLUSION}

This article compares the increase in self-consumption and the obtained savings of a PV prosumer with an EV, when smart charging and a BESS operated under a simple energy import minimization logic are considered. We find that in a typical Danish household smart charging increases selfconsumption from $29 \%$ to $54 \%$ and results in yearly savings of $220 €$, with a payback time of approximately 2 years. A BESS that yields similar results was found to be sized to $8 \mathrm{kWh} / 2 \mathrm{~kW}$, but has a payback time of approximately 40 years. It should be stressed that these results may depend on the prosumer's characteristics, such as inflexible consumption, PV size and EV usage, and savings could to some extent improve by more sophisticated control logics. However, the obtained 20 to 1 ratio indicates that with the current prices smart charging is a much more attractive option economically for typical $\mathrm{PV} / \mathrm{EV}$ prosumers. In our future work we will conduct a more thorough analysis by employing more advanced controllers that consider variables prices, and also consider different prosumer characteristics, driving patterns and retail prices. This will allow us to obtain more accurate and generalized results regarding the economic viability of the two solutions.

\section{ACKNOWLEDGEMENT}

The work in this paper is supported by the research projects ACDC (EUDP grant nr: 64019-0541) and CAR (EU-Interreg grant nr: STHB.03.01.00-SE-S112/17).

\section{REFERENCES}

[1] J. Hoppmann, J. Volland, T. S. Schmidt, and V. H. Hoffmann, "The economic viability of battery storage for residential solar photovoltaic systems - A review and a simulation model," Renewable and Sustainable Energy Reviews, vol. 39, pp. 1101-1118, 2014.

[2] M. Marinelli et al., "Electric vehicles demonstration projects - an overview across europe," in Universities Power Engineering Conference (UPEC), 2020 Proceedings of the 55th International, (Turin, Italy), pp. 1-6, 1-4 Sep. 2020.

[3] L. Calearo, M. Marinelli, and C. Ziras, "A review of data sources for electric vehicle integration studies," Renewable and Sustainable Energy Reviews, vol. 151, p. 111518, 2021.
[4] L. Calearo, A. Thingvad, K. Suzuki, and M. Marinelli, "Grid loading due to EV charging profiles based on pseudo-real driving pattern and user behavior," IEEE Transactions on Transportation Electrification, vol. 5, no. 3, pp. 683-694, 2019.

[5] C. Ziras, L. Calearo, and M. Marinelli, "The effect of net metering methods on prosumer energy settlements," Sustainable Energy, Grids and Networks, p. 100519, 2021

[6] A. S. Al-Ogaili, T. J. Tengku Hashim, N. A. Rahmat, A. K. Ramasamy, M. B. Marsadek, M. Faisal, and M. A. Hannan, "Review on scheduling, clustering, and forecasting strategies for controlling electric vehicle charging: Challenges and recommendations," IEEE Access, vol. 7, pp. 128353-128371, 2019.

[7] A. W. Thompson and Y. Perez, "Vehicle-to-Everything (V2X) energy services, value streams, and regulatory policy implications," Energy Policy, vol. 137, no. November 2019, p. 111136, 2020.

[8] G. Lee, T. Lee, Z. Low, S. H. Low, and C. Ortega, "Adaptive charging network for electric vehicles," 2016 IEEE Global Conference on Signal and Information Processing, GlobalSIP 2016 - Proceedings, pp. 891895, 2017.

[9] R. Fachrizal and J. Munkhammar, "Improved photovoltaic selfconsumption in residential buildings with distributed and centralized smart charging of electric vehicles," Energies, vol. 13, no. 5, 2020.

[10] I. Junquera Martínez, J. García-Villalobos, I. Zamora, and P. Eguía, "Energy management of micro renewable energy source and electric vehicles at home level," Journal of Modern Power Systems and Clean Energy, vol. 5, no. 6, pp. 979-990, 2017.

[11] G. Barone, G. Brusco, D. Menniti, A. Pinnarelli, G. Polizzi, N. Sorrentino, P. Vizza, and A. Burgio, "How smart metering and smart charging may help a local energy community in collective self-consumption in presence of electric vehicles," Energies, vol. 13, no. 6, 2020.

[12] I. B. Sperstad et al., "Cost-benefit analysis of battery energy storage in electric power grids: Research and practices," IEEE PES Innovative Smart Grid Technologies Conference Europe, vol. 2020-October, pp. 314-318, 2020.

[13] A. Cervi, M. Coppo, M. Agostini, and R. Turri, "Optimal management of Islanded Distribution Networks including Multi-Energy Storage Units,' 20th IEEE Mediterranean Electrotechnical Conference, MELECON 2020 - Proceedings, pp. 464-469, 2020.

[14] F. Simmini, M. Agostini, M. Coppo, T. Caldognetto, A. Cervi, F. Lain, R. Carli, R. Turri, and P. Tenti, "Leveraging demand flexibility by exploiting prosumer response to price signals in microgrids," Energies, vol. 13 , no. 12 , pp. 1-19, 2020.

[15] E. Nyholm, J. Goop, M. Odenberger, and F. Johnsson, "Solar photovoltaic-battery systems in Swedish households - Self-consumption and self-sufficiency," Applied Energy, vol. 183, pp. 148-159, 2016.

[16] C. T. Pham and D. Månsson, "Optimal energy storage sizing using equivalent circuit modelling for prosumer applications (Part II)," Journal of Energy Storage, vol. 18, no. April, pp. 1-15, 2018.

[17] B. Boeckl and T. Kienberger, "“'Sizing of PV storage systems for different household types"," Journal of Energy Storage, vol. 24, no. April, p. 100763,2019

[18] C. Cristea, M. Cristea, I. Birou, and R. A. Tirnovan, "Techno-economic evaluation of a grid-connected residential rooftop photovoltaic system with battery energy storage system: A Romanian case study," 2020 15th International Conference on Development and Application Systems, DAS 2020 - Proceedings, pp. 44-48, 2020.

[19] International Electrotechnical Commission, "IEC 61851 - Electric vehicle conductive charging system - Electric vehicles requirements for conductive connection of an a.c./d.c. power supply - IEC Webstore.".

[20] Transport DTU. The Danish national travel survey - TU. 2020, Available: https://www.cta.man.dtu.dk/english/national-travel-survey/what_is_tu. Accessed on July 2021.

[21] "Fronius.." https://www.fronius.com/en. Accessed March 2021

[22] El-grossisten.dk. Ladekabler til elbiler. Available online. https:// www.el-grossisten.dk/hus-og-have/ladekabler-til-elbiler.html. Accessed March 2021.

[23] Europe-SolarStore.com. Fronius Wattpilot Home 11 J. Available online. https://www.europe-solarstore.com/fronius-wattpilot-home-11-j. html. Accessed April 2021.

[24] DanskeSolceller.dk. Available online. https://danskesolceller.dk/. Accessed March 2021. 